\title{
Representações sociais de mulheres doadoras de leite humano sobre amamentação
}

\author{
Social representations women donors of human milk on breastfeeding \\ Representaciones sociales mujeres leche humana donantes sobre lactância
}

Márcia Maria Benevenuto de Oliveira ${ }^{1 *}$, Isília Aparecida Silva².

\begin{abstract}
RESUMO
Objetivo: Conhecer as representações sociais de doadoras de leite humano sobre amamentação. Métodos: Pesquisa qualitativa com 30 doadoras de leite humano, utilizando a Teoria das Representações Sociais, pelo método de análise de conteúdo, e as variáveis quantitativas pelo pacote estatístico SPSS. Resultados: As mulheres tinham entre 18 e 44 anos, 96,7\% tinham companheiro, tempo médio de doação foi 155 dias, maior volume doado foi 88 litros, tempo médio de aleitamento foi 371 dias. O tema experiência de amamentar emergiu das falas das mulheres com suas categorias: a história de amamentação na família, o lado bom da amamentação, desafios da amamentação, o leite humano é único e produzir bastante leite, ter o suficiente. Conclusão: Mulheres que amamentaram por longos períodos aderiram à doação de seu leite excedente. Suas representações sociais sobre amamentação foram construídas ao superarem as dificuldades advindas deste processo e por conseguirem vivenciar o lado bom da amamentação.
\end{abstract}

Palavras-chave: Bancos de Leite, Leite Humano, Aleitamento Materno, Lactação, Pesquisa Qualitativa.

\begin{abstract}
Objective: To know the social representations of human milk donors about breastfeeding. Methods: Qualitative research with 30 human milk donors, using the Theory of Social Representations, by the content analysis method, and quantitative variables by the SPSS statistical package. Results: Women were between 18 and 44 years old, $96.7 \%$ had a partner, average donation time was 155 days, highest donated volume was 88 liters, average breastfeeding time was 371 days. The theme breastfeeding experience emerged from the speeches of women with their categories: the history of breastfeeding in the family, the good side of breastfeeding, breastfeeding challenges, human milk is unique and produce enough milk, have enough. Conclusion: Women who breastfed for long periods adhered to the donation of their surplus milk. Their social representations about breastfeeding were built by overcoming the difficulties arising from this process and by being able to experience the good side of breastfeeding.
\end{abstract}

Keywords: Milk Banks, Human milk, Breastfeeding, Lactation, Qualitative research.

\section{RESUMEN}

Objetivo: Conocer las representaciones sociales de los donantes de leche humana sobre la lactancia materna. Método: Investigación cualitativa con 30 donantes de leche humana, utilizando la Teoría de las representaciones sociales, por el método de análisis de contenido, y variables cuantitativas por el paquete estadístico SPSS. Resultados: Las mujeres tenían entre 18 y 44 años, el 96.7\% tenía pareja, el tiempo

${ }^{1}$ Universidade Estadual de Londrina (UEL), Londrina - PR. *E-mail: benedioli@gmail.com

2 Universidade de São Paulo (USP), São Paulo - SP.

SUBMETIDO EM: 8/2019

ACEITO EM: 9/2019

PUBLICADO EM: 11/2019 
promedio de donación fue de 155 días, el volumen donado más alto fue de 88 litros, el tiempo promedio de lactancia fue de 371 días. El tema de la experiencia de la lactancia materna surgió de los discursos de las mujeres con sus categorías: la historia de la lactancia materna en la familia, el lado bueno de la lactancia materna, los desafíos de la lactancia materna, la leche humana es única y produce suficiente leche, tiene suficiente. Conclusión: Las mujeres que amamantaron durante largos períodos se adhirieron a la donación de su exceso de leche. Sus representaciones sociales sobre la lactancia materna se construyeron al superar las dificultades derivadas de este proceso y al poder experimentar el lado bueno de la lactancia materna.

Palabras clave: Bancos de leche, Leche humana, Lactancia materna, Lactancia, Investigación cualitativa.

\section{INTRODUÇÃO}

É sabido que o aleitamento materno exclusivo é de extrema importância nas primeiras fases de vida da criança e que este é o melhor alimento que esta pode receber na fase em que se encontra. O leite humano é caracterizado como a resposta da natureza, no que tange à pergunta de qual melhor alimento para o homem crescer e se desenvolver (VINAGRE RD e DINIZ EMA, 2002).

Por muito tempo a amamentação exclusiva ao recém-nascido foi considerado praticamente a forma única e natural de alimentá-lo, no entanto, com a industrialização este fato se tornou uma exceção, estando presente os mais diversos e variados alimentos industrializados para os primeiros meses de vida (ACCIOLY E, et al., 2003).

A história de Rômulo e Remo, presente na mitologia Grega, conta a forma como era alimentados, sendo estes por uma loba e Zeus, por uma cabra. Outro fato que marcou a história é que os egípcios, babilônios e hebreus mantinham a tradição, o tempo destinado a amamentação, que correspondia há três anos (BITAR MAF, 1995).

Na história, já existia casos da impossibilidade da mãe alimentar os recém-nascidos, desta forma, os povos gregos e romanos contava com as amas-de-leite para que possam amamentar seus filhos. Amas-de-leite eram escravas que tinham como atividade laboral responsável a de amamentar os filhos dos ricos, cujas mães estavam incapacitadas deste ato. Vale salientar que esta prática não era frequente (VINAGRE RD e DINIZ EMA, 2002).

A amamentação começou a aumentar com o surgimento do cristianismo, o que acabou proporcionando além da prática em amamentar, a proteção a crianças se fez presente. Essa proteção transcendia para as crianças consideradas órfãs e abandonadas, o que proporcionava um olhar voltada a elas (VINAGRE RD e DINIZ EMA, 2002).

Embora neste momento, principalmente na região da França e Inglaterra, o aleitamento materno exclusivo estava tendendo a diminuir, chama a atenção que, com o descobrimento da América foi possível desvelar que os povos nativos tinham a prática de amamentar suas crianças por um tempo aproximado de 3 a 4 anos (SILVA AAM, 1990).

Outro importante momento é que no século XVII, a prática da amamentação exclusiva, que foi apontada por estudos, deixa de ser vista pela população europeia como uma prática não importante, deixando de existir a admiração presente nos anos anteriores. A partir deste momento as amas-de-leite, citadas anteriormente passam a assumir este papel na sociedade, o que retira o contato mãe bebê (BITAR MAF, 1995).

Frente a este cenário foi evidenciado que a taxa de mortalidade infantil aumentou drasticamente após sessar o aleitamento materno exclusivo. Este fato marcou a região de Dublin, cuja taxa de mortalidade infantil chegou a $99,6 \%$ e uma das justificativas é que neste ambiente não contavam com ama-de-leite. Em Paris esta taxa chegou a $80 \%$, já em Londres passou de $50 \%$, e o que impacta negativamente nessas dois contextos, é que em ambos a ama-de-leite se faziam presentes e tinhas suas atividades regulares (BITAR MAF, 1995). 
Dentre todos os estudos realizados nas diferentes regiões, a Inglaterra destacou-se por apresentar a menor taxa de mortalidade infantil. Este fato se justifica pelo projeto conhecido como Cadogan, este criou diversos cuidados que se deveria ter com as crianças no que tange a amamentação com as amas-de-leite, bem como se propuseram a incluir outros alimentos à criança mais tardiamente, e dessa forma, impactou positivamente para o resultado que alcançaram (BITAR MAF, 1995).

As doenças das crianças e seus remédios é um tratado que foi escrito por Nils Rosen von Rosentein e publicado em 1764, neste tratado é apresentado diversos ensinamentos para com as crianças, dentre os ensinamentos destaca-se que para uma criança se desenvolver de forma adequada, esta deve ingerir o aleitamento materno exclusivo (ICHISATO SMT e SHIMO AKK, 2002).

É certo que houve com o tempo uma diminuição drástica no que diz respeito ao aleitamento materno exclusivo, uma vez que durante a história, houve uma média de $15 \%$ a $25 \%$ de mortes em crianças, que inclusive, em crianças consideradas abandonadas e órfãs e que não possuíam nenhuma possibilidade de ter uma mãe substituta a média de crianças mortas chegou a $90 \%$. Entendendo este processo de aleitamento materno exclusivo no final do século XIX como ponto dificultado, esta prática se constituía entre a vida e a morte (VINAGRE RD e DINIZ EMA, 2002).

Amamentar é uma excelente prática de vínculo, afeto, proteção e nutrição para a criança. Além de promover a saúde integral da dupla mãe/bebê, reduz a mortalidade infantil (BRASIL, 2015).

Crianças amamentadas exclusivamente têm apenas $12 \%$ de risco de morte comparadas com aquelas não amamentadas (VICTORA CG, et al., 2016). Recomenda-se aumentar as taxas de aleitamento materno exclusivo (AME) como prioridade para reduzir as mortes infantis (VICTORA CG, et al., 2016).

A última pesquisa nacional sobre o aleitamento materno (AM), realizada em 2010 nas capitais e Distrito Federal, encontrou 41\% de AME em crianças de 0 a 6 meses; a duração mediana do AM passou de 295,9 dias em 1999 para 341,6 dias em 2008 (VENANCIO SI, et al., 2010).

A melhor prática em Unidade de Terapia Intensiva Neonatal é incentivar e apoiar as mães a amamentar seu bebê prematuro diretamente no seio ou extrair seu leite para alimentar o filho (SPATZ DL, 2012). Outra estratégia é utilizar leite humano pasteurizado. A política pública de saúde responsável por essa ação é a Rede Brasileira de Bancos de Leite Humano (rBLH), regulamentada pelo Ministério da Saúde em 1988 (MATTAR MJG, 2011).

Pouco se sabe sobre a experiência e a visão que mulheres doadoras têm sobre seu próprio processo de amamentar. Conhecer questões mais subjetivas e do entorno delas quanto às suas representações sobre amamentação e seu ato de amamentar pode facilitar a ação dos profissionais na abordagem e na proposta de sua adesão à doação do leite, de forma espontânea e autônoma. Esta pesquisa objetivou compreender as representações sociais que permeiam o processo de AM para mulheres que praticam a doação.

\section{MÉTODOS}

Optou-se pela pesquisa qualitativa por incorporar a questão do significado e da intencionalidade como inerentes aos atos, às relações e às estruturas sociais (MINAYO MCS, 2008).

O estudo foi desenvolvido em Londrina-PR, e o cenário da pesquisa foi o Banco de Leite Humano (BLH) do Hospital Universitário, que integra a rBLH.

Participaram desta pesquisa doadoras de leite humano cujo critério de inclusão foi estarem cadastradas no BLH do hospital. O critério de saturação dos dados qualitativos na entrevista definiu o número de participantes em 30. Coletaram-se os dados de julho de 2015 a março de 2016, por entrevista no domicílio das participantes, com data e horário marcados previamente. Fez-se a identificação e seleção das mulheres por consulta à ficha de cadastro de doadoras no BLH. A primeira parte da entrevista consistiu na aplicação de um formulário para coleta dos dados objetivos: idade materna, local de moradia, escolaridade, situação 
conjugal, trabalho fora do lar, tipo de trabalho, total de filhos, tipo de parto, local do nascimento da criança, número de vezes em que foi doadora, volume doado, tempo de doação e tempo de AM praticado.

No momento seguinte, fez-se uma entrevista em profundidade para coletar os dados qualitativos, lançando-se uma pergunta norteadora para a mulher manifestar o que o amamentar representara para ela. Todos os dados foram coletados após todos os esclarecimentos e assinatura do Termo de Consentimento Livre e Esclarecido.

Para análise das variáveis quantitativas, foram calculadas frequências, médias e medianas por pacote estatístico. Para análise dos dados qualitativos, utilizou-se o método da análise de conteúdo proposto por Bardin, por favorecer a exploração das relações que os indivíduos mantêm em sua vida e por ter uma suficiência epistemológica que a justifica.

O projeto foi aprovado pelo Comitê de Ética em Pesquisa Envolvendo Seres Humanos da Escola de Enfermagem da Universidade de São Paulo, sob o Parecer № 1.105.438.

\section{RESULTADOS}

O perfil das 30 participantes da pesquisa (Tabela 1) evidenciou que a idade variou de 18 a 44 anos, com média de 32,73 anos, a maioria (93,3\%) residia em Londrina, 96,7\% estavam com companheiro, 86,7\% tinham educação superior completa, $83,3 \%$ submeteram-se ao parto por cesariana, $40 \%$ tinham apenas um filho, $50 \%$ tinham dois, e $10 \%$ tinham três filhos.

Entre as $23(76,7 \%)$ doadoras que exerciam trabalho remunerado fora de casa, havia profissionais da saúde (30,0\%), profissionais administrativas (13,3\%), cabeleireiras/esteticistas (10\%), bancárias $(6,7 \%)$, professoras $(6,7 \%)$, cozinheiras $(3,3 \%)$, empresárias $(3,3)$ e personal trainer $(3,3 \%)$. Dentre as doadoras, $53,3 \%$ haviam doado leite uma única vez, e $46,7 \%$ doaram duas ou três vezes.

Tabela 1 - Características das mulheres doadoras de leite humano para o BLH. Londrina, PR, Brasil, 2016 $(n=30)$.

\begin{tabular}{|c|c|c|}
\hline Variável & $\mathbf{N}$ & $\%$ \\
\hline \multicolumn{3}{|l|}{ Tipo de parto } \\
\hline Cesárea & 25 & 83,3 \\
\hline Vaginal & 5 & 16,7 \\
\hline \multicolumn{3}{|l|}{ Local do parto } \\
\hline Hospital Evangélico de Londrina & 20 & 66,7 \\
\hline Hospital Mater Dei de Londrina & 3 & 10,0 \\
\hline Hospital Universitário de Londrina & 2 & 6,7 \\
\hline Outros hospitais de Londrina e região & 5 & 16,6 \\
\hline \multicolumn{3}{|l|}{ Total de filhos vivos } \\
\hline 1 & 12 & 40,0 \\
\hline 2 & 15 & 50,0 \\
\hline 3 & 3 & 10,0 \\
\hline \multicolumn{3}{|l|}{ Vezes em que foi doadora } \\
\hline 1 & 16 & 53,3 \\
\hline 2 & 13 & 43,3 \\
\hline 3 & 1 & 3,3 \\
\hline \multicolumn{3}{|l|}{ Situação conjugal } \\
\hline Com companheiro & 29 & 96,7 \\
\hline Sem companheiro & 1 & 3,3 \\
\hline \multicolumn{3}{|l|}{ Escolaridade materna } \\
\hline Ensino Médio ( $2^{\circ}$ grau) & 4 & 3,3 \\
\hline Educação Superior ( $3^{\circ}$ grau) & 9 & 30,0 \\
\hline Pós-Graduação & 17 & 56,7 \\
\hline
\end{tabular}

Fonte: Oliveira MMB, Silva IA, 2019. 
As doadoras de leite humano souberam do BLH de diferentes formas, no entanto destaca-se que mais de metade delas referiram que esta informação foi por meio dos profissionais da saúde e pelos meios de comunicação (Tabela 2).

Tabela 2 - Distribuição das doadoras do BLH segundo o modo como ficou sabendo do banco de leite. Londrina, PR, Brasil, $2016(n=30)$

\begin{tabular}{lll}
\hline Como ficou sabendo do blh & $\mathbf{N}$ & $\%$ \\
\hline Profissionais da saúde & 10 & 33,3 \\
Meios de comunicação & 6 & 20,0 \\
Trabalha na área & 5 & 16,7 \\
Familiar & 3 & 10,0 \\
Amiga & 3 & 10,0 \\
Ex-doadora & 2 & 6,7 \\
Curso de gestante & 1 & 3,3 \\
\hline TotaL & $\mathbf{3 0}$ & $\mathbf{1 0 0 , 0}$ \\
\hline
\end{tabular}

Fonte: Oliveira MMB, Silva IA, 2019.

O tempo de doação de leite materno chegou a ultrapassar 12 meses, no entanto identificou-se que a maioria das mulheres doavam por 3 a 6 meses o que representa $40,0 \%$ das doações, seguido das que doavam por até 3 meses representando $26,7 \%$ (Tabela 3 ).

Tabela 3 - Distribuição das doadoras do BLH segundo o tempo de doação de leite. Londrina, PR, Brasil, 2016 $(\mathrm{n}=30)$

\begin{tabular}{lll}
\hline Meses & $\mathbf{N}$ & $\%$ \\
\hline Até 3 & 8 & 26,7 \\
3 а 6 & 12 & 40,0 \\
6 a 9 & 6 & 20,0 \\
9 a 12 & 3 & 10,0 \\
>12 & 1 & 3,3 \\
\hline TOTAL & 30 & $\mathbf{1 0 0 , 0}$ \\
\hline
\end{tabular}

Fonte: Oliveira MMB, Silva IA, 2019.

O tempo de doação para o BLH variou de 1 a 415 dias. O volume doado variou de 400 mililitros a 88 litros. Nenhuma das doadoras amamentou menos que seis meses, e duas amamentaram por mais de dois anos (Tabela 4).

Tabela 4 - Distribuição das doadoras do BLH segundo o tempo de aleitamento materno. Londrina, PR, Brasil, $2016(n=30)$.

\begin{tabular}{lll}
\hline Meses & $\mathbf{N}$ & $\%$ \\
\hline 6 a 9 & 9 & 30,0 \\
9 a 12 & 6 & 20,0 \\
12 a 24 & 13 & 43,3 \\
$>24$ & 2 & 6,7 \\
\hline TOTAL & $\mathbf{3 0}$ & $\mathbf{1 0 0 , 0}$ \\
\hline
\end{tabular}

Fonte: Oliveira MMB, Silva IA, 2019.

Quanto ao estudo das representações sociais das doadoras sobre amamentação, os dados permitiram construir um tema que englobava experiências e concepções acerca de sua experiência em amamentar. A percepção dessas mulheres sobre a amamentação foi construída no seu universo consensual, tendo como 
base o conhecimento de senso comum, principalmente da história de amamentação na família. Segundo elas, essa prática é um desafio, mas que superam e se mantém firme no propósito de produzir leite suficiente para seu filho. A história de amamentação na família: As mulheres trazem fortemente consigo o saber de senso comum construído e aprendido das experiências das mulheres da família e de seu entorno social.

Minha avó sempre amamentou todos os filhos dela, mas minha mãe só amamentou um dos filhos, porque era muito nervosa. (E18)

Ao comparar suas experiências com outras, especialmente as da família, elaboram suas percepções sobre amamentar.

\section{Eu fiquei muito feliz quando vi que tinha muito leite. (E18)}

As experiências que elas têm no seu contexto podem construir uma experiência de amamentação muito valorizada, embora nem todas sejam exitosas. Em sua experiência concreta de amamentar, os demais atores têm papel importante, sendo incluídos em seu universo como referência para avaliar e comparar sua prática de amamentar, podendo influenciar as ações e percepções de quem não partilhava da mesma crença.

No início, meu marido não incentivava a amamentação e a doação, acho que porque minha sogra não amamentou. Ela sempre dizia que não gostava. Mas meu marido me apoiou e passou a valorizar. Ele sempre me ajudou. (E21)

Nessa perspectiva, elas reconhecem que sua experiência é única e que podem ter uma história diferente de outras mulheres com quem conviveram, fazendo sua própria história.

Minha mãe não teve história de amamentação. Mas eu fiz diferente e não tive nada, nem mastite, nada, nada, nada. Eu tive muito leite, adorava amamentar, fiz livre demanda, então era uma loucura! (E22)

O lado bom da amamentação: A concepção da maternidade, construída desde antes da gravidez ou durante o processo de gestar, traz em si o desejo de poder amamentar o filho, produzir leite suficiente para garantir a alimentação da criança e dar vazão a uma realização pessoal de ser mãe e provedora do filho.

Em primeiro lugar, eu queria amamentar o meu bebê. E isso NÃO veio da minha infância. A gestação motivou meu desejo para amamentar. [...] Fui estudando e vi que era o melhor para mim e meu filho; busquei muitas informações [...] (E5)

O reconhecimento acerca dos atributos do leite materno tem lugar numa dimensão objetiva da realidade, quando elas tomam para si informações do universo reificado a respeito do leite e do seu valor para a saúde e sobrevida da criança, atribuindo um valor concreto ao leite que produzem.

Eu sou fisioterapeuta e fiz residência em pediatria. Então, quando passei pela UTI pediátrica [...] a gente sabia da importância que o leite materno tem. (E8)

A amamentação também tem um lado utilitarista e se apresenta na praticidade de um método rápido e pronto de alimentar uma criança.

Pra qualquer lugar que eu vou, meu marido pergunta: 'Tá esquecendo alguma coisa?' Não, meus dois peitos estão aqui! (E6)

As mulheres compreendem que a amamentação lhes proporciona alguns benefícios objetivos percebidos na sua saúde.

A gente vive hoje de um jeito que as pessoas dão muito valor pra voltar a ter um peito bonito, voltar a ter um corpo bonito. E na verdade, a mãe emagrece mais rápido ainda se ela estiver amamentando. (E6)

Esse conjunto de elementos converge para uma percepção ampla do processo de amamentar e projeta nessa experiência a oportunidade de construção de vínculo entre ambos. 
É uma experiência única [...] quem amamenta sabe, não tem o que falar. Você cria uma relação com seu filho que só você pode ter essa relação, mais ninguém, ninguém pode fazer mais por ele do que você. (E20)

Os desafios da amamentação: Vivenciar a amamentação representa também vencer desafios objetivados nas dificuldades resultantes das intercorrências mamárias, desconfortos causados pelas mamas cheias ou cansaço do processo contínuo de atendimento das demandas da criança e de outros atores de seu entorno.

[...] passei os piores desafios, porque minha mama rachou, eu tive mastite, eu tive muito leite, ele desceu muito rápido e eu precisei do acompanhamento de uma enfermeira. Eu acho que realmente eu venci! (E23)

O despreparo e o desconhecimento sobre a realidade dessa prática e sobre como manejar a amamentação também são elementos significativos no enfrentamento das dificuldades que trouxeram dúvida quanto à continuidade da amamentação, e na primeira gestação, essas dificuldades se manifestam mais intensamente.

\section{[...] amamentar não é fácil, principalmente no começo! (E6)}

A minha primeira experiência de amamentar o meu primeiro filho foi muito difícil. (E20)

Para as mulheres com uma segunda ou até mais experiências, a prática adquirida de amamentar e a atribuição de significados em situação semelhante as instrumentalizam para lidar com a situação desafiadora de maneira diferente.

Com o segundo filho foi mais fácil. Mas mesmo assim tive mastite. (E20)

Atores sociais do universo reificado, representados pelos profissionais que as assistem, são observados de forma crítica em relação à sua prática, uma vez que as mulheres esperam deles coerência com o discurso profissional, pois suas ações evidenciam a negação ou a não aplicação desse conhecimento.

Ainda assim têm mães que acham que o leite é fraco, inclusive os pediatras passam isso pras mães, muitas vezes, e por mais que você é amiga, você dá algum tipo de orientação, você não tem como impor, porque se o pediatra que é o pediatra falou, elas acabam acreditando muito. (E25)

A conduta profissional de prescrição precoce de fórmulas lácteas contribui para aumentar a crença de que o leite humano é fraco. Igualmente quando se oferecem às mães alternativas que não valorizam suas dificuldades na amamentação, elas podem ser facilmente desestimuladas da continuidade desse processo se, nesse momento, não estiverem confiantes para amamentar.

O médico diz o quanto é importante [amamentar], mas ao mesmo tempo ele te dá uma alternativa muito fácil. Numa hora de dificuldade, você agarra nessa alternativa. Pra mim, isso é o começo do fim. (E23)

O leite humano é único: Mesmo tendo vivenciado algum tipo de experiência familiar relacionada à amamentação, as experiências dessas mulheres são únicas e as surpreendem, sobretudo diante dos resultados do desenvolvimento e crescimento de seu filho.

Eu acho que é um alimento tão singular, tão único que a gente tem pra oferecer pra criança. (E6)

Suas falas revelam crenças sobre o leite humano, construídas a partir da veiculação de mensagens do universo reificado, que chegam até elas por diversas fontes.

Essa crença que as mulheres demonstram em relação aos atributos do leite influi nas suas atitudes em decidir amamentar.

Porque tá completinho [...] tem água, tem vitamina, gorduras, fatores de proteção, tudo o que a criança precisa. (E6) 
Produzir bastante leite, ter o suficiente: $O$ processo de amamentar também preocupa quanto a produzir leite em quantidade suficiente para o filho. Quando percebem que têm leite em quantidade suficiente, ou até mais que suficiente, sentem-se confiantes por prover a alimentação da criança.

Eu sempre tive uma grande preocupação se teria leite para amamentar. E eu não tinha essa expectativa que eu tivesse bastante leite. Eu [enfaticamente] tenho bastante leite! (E3)

A ideia de produzir bastante leite é construída e adquirida em contextos familiares e sociais. Insistindo no peito e amamentando em livre demanda, percebem que sua produção láctea aumenta ainda mais.

Só insisti no peito e isso foi aumentando ainda mais o volume, porque eu sempre amamentei em livre demanda. (E5)

Sentem-se realizadas quanto a poder ofertar o alimento que seus filhos precisam.

Graças a Deus fui abençoada em ter leite suficiente pra minha filha... (E7)

\section{DISCUSSÃO}

Nesta pesquisa, 96,7\% das mulheres tinham companheiros, semelhante ao encontrado na literatura (SILVA ES, et al., 2015; SOUSA SOARES L, et al., 2016). Tal resultado torna-se relevante ao se considerar que o pai constitui um apoio essencial para o sucesso da mulher que amamenta (SILVA BT, et al., 2012).

Quanto à escolaridade, 86,7\% das mulheres tinham educação superior completa, com graduação ou pósgraduação. Para alguns autores, há relação entre maior tempo de $\mathrm{AM}$ e grau de instrução materna (FALEIROS FTV, et al., 2006).

O tipo de parto para $83,3 \%$ dessas mulheres foi a cesariana, índice preocupante e condizente com os encontrados em inquérito nacional, que chegaram a $88 \%$ dos nascimentos no setor privado, quando 0 determinado pela Organização Mundial da Saúde para partos cirúrgicos é 15\% (LEAL MC, et al., 2014).

Outra pesquisa com brasileiras destacou que as mulheres atendidas no setor hospitalar privado tiveram $87,5 \%$ de cesarianas, com aumento da decisão por este tipo de parto no final da gestação, independentemente de diagnóstico de complicações. Tanto no setor privado quanto na rede pública, a proporção de cesarianas foi superior à desejada pelas participantes investigadas (DOMINGUES RMSM, et al., 2014).

Das 30 participantes, 23 (76,7\%) exerciam trabalho remunerado fora de casa, semelhante ao obtido em pesquisa com doadoras de leite humano em Tubarão, Santa Catarina, em que 55,5\% eram assalariadas (LOURENÇO D, et al., 2012).

Nesta pesquisa, o tempo médio de doação foi de 155 dias, resultado um pouco menor que o encontrado entre doadoras residentes em Madri, Espanha, de 189 dias (COLOMINA GS, et al., 2014).

Em relação ao tempo de AM das doadoras desta pesquisa, observou-se que nenhuma amamentou por menos que seis meses, $50,0 \%$ amamentaram por mais de um ano e duas o fizeram por mais de dois anos. A mediana do AM nesse grupo de mulheres foi de 338 dias.

A vivência dessas doadoras sustenta sua perspectiva de amamentação numa trajetória pessoal e coletiva de experiências de amamentação. O meio relacional familiar é a mais comum e importante referência para a mãe no processo de amamentar, por ser o mais próximo dela (MULLER FS e SILVA IA, 2009).

A influência da família, em especial das mães, foi objeto de uma pesquisa que analisou a duração do AM em duas gerações. O resultado evidenciou que mães não amamentadas tiveram risco relativo de 1,34 de não amamentar seus filhos quando comparadas às que foram amamentadas (HORTA BL, et al., 2007).

Pôde-se observar que as vivências familiares permitem à espécie humana aprender a amamentar, reforçando que o AM é um bem social compartilhado e transgeracional. Isso exige dos profissionais maior 
entendimento dos processos evolutivos de cada família, para melhor apoiar a mulher que amamenta (ARAÚJO LDS, 2016).

Quanto à contradição entre benefícios e dificuldades vivenciados pela mulher que amamenta foi encontrada em uma pesquisa em que as mulheres relataram cansaço com o processo de amamentar pela solicitação constante do filho, tempo a ser dedicado ao bebê e exigências ininterruptas que demandam do ser mãe, sendo necessária também a ajuda da equipe de saúde para superar essas dificuldades (OSÓRIO CM e QUEIROZ ABA, 2007).

Observou-se em um estudo e nesta pesquisa a importância do vínculo efetivo entre puérpera, família e profissionais de saúde, gerando confiança e segurança para essa mulher obter sucesso no processo de amamentar (BOFF ADG, et al., 2015).

A representação do leite materno como alimento singular é um dos pilares para essa mulher valorizar ou não sua prática de amamentar. Todavia, além da qualidade do leite, a percepção de ter quantidade de leite suficiente para o filho, ou mesmo excedente, está presente nas experiências das mulheres como forte indicador de segurança e realização para a nutriz (ROCHA NB, et al., 2010).

\section{CONCLUSÃO}

As percepções das mulheres doadoras sobre o aleitamento materno refletem sobre o próprio processo de amamentar em suas dimensões subjetivas e objetivas, sendo construída com base em seu universo consensual, tendo como base o conhecimento de senso comum. A doação de leite excedente esteve presente em mulheres que amamentaram por longos períodos e o fato de superarem suas dificuldades e vivenciarem boas experiências na amamentação é que foram construídas as representações sociais sobre a amamentação.

\section{REFERÊNCIAS}

1. ARAÚJO LDS. Abordagem sistêmica na prática do aleitamento materno. Pediat Dia. V. 16, n. 54, p. 22-5, 2016.

2. BARDIN L. Análise de conteúdo. Lisboa: Edições 70; 2010.

3. BOFF ADG, et al. Aspectos socioeconômicos e conhecimento de puérperas sobre o aleitamento materno. Audiology-Communication Research, v. 20, n. 2, p. 141-145, 2015.

4. BRASIL. Saúde da criança: aleitamento materno e alimentação complementar. 2015.

5. COLOMINA GS, et al. Características de las mujeres donantes de un banco de leche materna y relación con el tiempo de donación. In: Anales de Pediatría. Elsevier Doyma, 2014. p. 236-241.

6. DOMINGUES RMSM, et al. Processo de decisão pelo tipo de parto no Brasil: da preferência inicial das mulheres à via de parto final. Cadernos de Saúde Pública, v. 30, p. S101-S116, 2014.

7. FALEIROS FTV, et al. Aleitamento materno: fatores de influência na sua decisão e duração. Revista de Nutrição, p. 623-630, 2006.

8. HORTA BL, et al. Duração da amamentação em duas gerações. Revista de Saúde Pública, v. 41, p. 13-18, 2007.

9. LEAL MC, et al. Intervenções obstétricas durante o trabalho de parto e parto em mulheres brasileiras de risco habitual. Cadernos de Saúde Pública, v. 30, p. S17-S32, 2014.

10. LOURENÇO D, et al. Perfil das doadoras do banco de leite humano do Hospital Nossa Senhora da Conceição, Tubarão/SC. Arq Catarin Med, v. 41, n. 1, p. 22-7, 2012.

11. MATTAR MJG. Organização do banco de leite humano. In: Aprile MM, Feferbaum R. Banco de leite Humano. São Paulo: Atheneu; 2011. p. 87-91.

12. MINAYO MCS. O desafio do conhecimento: pesquisa qualitativa em saúde. 11 ed. São Paulo: HUCITEC; 2008.

13. MULLER FS, SILVA IA. Representações sociais de um grupo de mulheres/nutrizes sobre o apoio à amamentação. Revista Latino-Americana de Enfermagem, v. 17, n. 5, 2009.

14. OSÓRIO CM, QUEIROZ ABA. Representações sociais de mulheres sobre a amamentação: teste de associação livre de idéias acerca da interrupção precoce do aleitamento materno exclusivo. Escola Anna Nery Revista de Enfermagem, v. 11, n. 2, p. 261-267, 2007.

15. ROCHA NB, et al. O ato de amamentar: um estudo qualitativo. Physis: Revista de Saúde Coletiva, v. 20, p. 12931305, 2010. 
16. SILVA BT, et al. Apoio paterno ao aleitamento materno: uma revisão integrativa. Revista Paulista de Pediatria, v. 30, n. 1, p. 122-130, 2012.

17. SILVA ES, et al. Doação de leite materno ao banco de leite humano: conhecendo a doadora. DEMETRA: Alimentação, Nutrição \& Saúde, v. 10, n. 4, p. 879-889, 2015.

18. SOUSA SOARES L, et al. Autoeficácia em amamentação de doadoras de leite materno humano. Journal of Nursing UFPE/Revista de Enfermagem UFPE, 2016.

19. SPATZ DL. Inovações no fornecimento de leite humano e amamentação para bebês que necessitam de cuidados intensivos. Revista de Enfermagem Obstétrica, Ginecológica e Neonatal , v. 41, n. 1, p. 138-143, 2012.

20. VENANCIO SI, et al. Breastfeeding practice in the Brazilian capital cities and the Federal District: current status and advances. Jornal de pediatria, v. 86, n. 4, p. 317-324, 2010.

21. VICTORA CG, et al. Breastfeeding in the 21st century: epidemiology, mechanisms, and lifelong effect. The Lancet, v. 387, n. 10017, p. 475-490, 2016.

22. VINAGRE RD, DINIZ EMA. O leite humano e sua importância na nutrição do recém-nascido prematuro. São Paulo: Atheneu, 2002.

23. ACCIOLY E, et al. Manual em Obstetrícia e Pediatria. 3. ed. Rio de Janeiro: Cultura Médica, 2003.

24. BITAR MAF. Aleitamento materno: um estudo etnográfico sobre os costumes crenças e tabus ligados a esta prática. 1995. Tese de Doutorado. [dissertação]. Belém (PA): Centro de Ciências da Saúde Departamento de Enfermagem/Universidade Federal do Pará.

25. SILVA AAM. Amamentação: fardo ou desejo? Estudo histórico social dos deveres e práticas sobre aleitamento na sociedade brasileira. 1990. [dissertação]. Ribeirão Preto (SP): Faculdade de Medicina de Ribeirão Preto/USP.

26. ICHISATO SMT, SHIMO AKK. Revisitando o desmame precoce através de recortes da história. Rev. latinoam. enferm, v. 10, n. 4, p. 578-585, 2002. 